\title{
Theoretical foundations of the formation of the readiness of future teachers to work in the regional digital educational environment
}

\author{
Oksana Kitikar $^{1}$, Natalia Levchenko ${ }^{2, *}$ \\ ${ }^{1}$ Kaluga State University named after K.E. Tsiolkovsky, Kaluga \\ ${ }^{2}$ Taras Shevchenko Pridnestrovian State University, Faculty of Physical Culture and Sports, Tiraspol, \\ Pridnestrovskaia Moldavskaia Respublika
}

\begin{abstract}
The purpose of the article is to characterize the conceptual foundations of the content and structure of the regional system of teacher education in the digital educational environment. The directions of modernization of the teacher training system are based on the substantiation of scientific approaches to the ways of organizing the interaction of the subjects of the educational process in the region with an emphasis on eliminating the professional deficits of teachers, on the formation of a new type of competencies among teachers for the implementation of pedagogical activities at a high level in a regional digital educational environment, taking into account its specifics.
\end{abstract}

\section{Introduction}

The modernization of the Russian education system is closely related to the reform of the foundations for the training of modern teachers. Fundamental changes in the requirements for the organization of the process of teaching and upbringing in educational institutions and for the results of education of students cannot but touch upon the problem of the quality of training of pedagogical personnel in Russia.

Modern trends in the development of education associated with a change in the place and format of education, the emergence, along with traditional, network and online learning models, the presence of diversification and standardization in the unity of the educational space, etc., affect the need to change strategic guidelines when building a continuous education system for teachers. Pedagogical activity is important in the context of ubiquitous education, which is a totally universal type of development of modern society.

Scientists Bolotov V.A., Levitsky M.L., Remorenko I.M., Serikov V.V. the main priorities for the modernization of teacher education are:

- the allocation of aspects of purposeful socialization of a person as an abstract characteristic of pedagogical activity: designing the content of education on pedagogically transformed cultural phenomena; creating a motivational basis for the assimilation of this content and the implementation of targeted support for the student;

\footnotetext{
* Corresponding author: natai-levche@mail.ru
} 
- the conditions for mastering the variety of types of pedagogical activity by the teacher is always conditioned by the content of the conditions of his training;

- determination as the dominant function of the teacher - the formation of students' experience of subjectivity - the ability to critical analysis of information, goal-setting, entry into cultural and network communities;

- reliance on fundamental scientific research in the design of the content of pedagogical education and the construction of a unified field of professional actions of the teacher;

- the need to use domestic and foreign advanced pedagogical experience in building a system of professional socialization of a teacher: from training at a university to building a successful professional career;

- taking into account the factor of active formation of an open educational space with the following characteristics in the construction of meaningful teacher training with the following characteristics: the multiplicity of subjects of pedagogical influence on the student; deinstitutionalization of education; powerful impact on learners of the digital environment.

These factors, of course, must be taken into account when reconstructing the teacher training system, however, the very environment in which pedagogical education is carried out must be part of a single educational space on a national and global scale in order to be capable of competition.

Large-scale digitalization has led to the formation of not only a new information educational space at different levels: global, state, regional, municipal and local, but also contributed to the formation of digital educational environments. Their development is especially important at the regional level, since the constituent entities of the Russian Federation are legally assigned the obligation to implement the citizens' right to education. The regions have also been given great powers in the field of organizing the content and technological support of the teacher training system in accordance with their characteristics and staffing requirements. However, in modern pedagogical research, the problem of organizing the pedagogical system has not been sufficiently solved to ensure the readiness of teachers to carry out high-quality pedagogical activities in the digital educational environment educated in the regions, which leaves a negative imprint on the quality of education in the constituent entities of the Russian Federation in general.

\section{Methodology}

The research methods are the analysis of modern experience of organizing teacher education in the region, examination of the possibilities of the digital educational environment of the region, systematization, structural and content analysis of models of teacher education in the universities of the Russian Federation.

The object of the research is the regional system of pedagogical education, created in Kaluga and the Kaluga region, in the Nizhny Novgorod region. The main source of information is regulatory documents in the field of higher pedagogical education of the Russian Federation and the organization of teacher training in the constituent entities of the Russian Federation, as well as curricula and training programs for students of pedagogical universities and educational institutions of additional professional education for teachers in the regions.

The logic of the research consists in defining the theoretical aspects of the structural foundations of the content and technological components of the teacher training system in higher educational institutions and educational institutions of additional professional education in the Russian Federation. The research was carried out in several stages, each of which solved a specific problem. 


\section{Results}

The first stage of the study was devoted to determining the factors influencing the formation of the digital educational environment of the region as an integral part of the Russian educational space, as well as the main characteristics of the network professional community of teachers of the constituent entities of the Russian Federation, based on the specifics of the requirements for the pedagogical activity of the region itself and the set of requirements for the organization of the system pedagogical education based on the regulatory requirements of the educational and professional standards of the state. In the field of organizing the system of pedagogical education at different levels, several approaches can be distinguished: the normative approach - the institutional structure of educational institutions strictly regulated by legislation, represented by a network of institutions of secondary vocational education and higher education, institutions of additional vocational education; structural and content-based approach - teacher training is carried out in accordance with the structure of an educational institution on the basis of federal state educational standards for pedagogical education and basic educational programs; the competence-based approach is implemented in institutions of secondary vocational and higher education, while the consistency of the application of this approach in institutions of additional professional education for teachers has not been determined. The regional approach is substantiated by the specifics of the constituent entities of the Russian Federation, associated not only with human resources, but also with the need to train teachers for the implementation of regional socio-economic policy in the field of upbringing of the younger generation, based on taking into account demographic, ethnic, linguistic, cultural and national characteristics, as well as the specifics of education. local digital educational environment. An important aspect of the current situation in the field of education is, on the one hand, the need to preserve pedagogical traditions and their integration into the content of teacher training and the transformation of the traditional content and technological basis of the pedagogical education system associated with largescale digitalization of society, on the other.

The criteria for assessing the quality of teacher education were selected based on its characteristics, taking into account the features and essence of the convergence of the traditional and information educational environment, as well as on the basis of an analysis of the possibility of taking into account the following regional features in the process of teacher training: multiculturalism, bilingualism, organization of network interaction between the subjects of the system teacher education within the region and between regions.

The characteristics of teacher education are:

- goals: the formation of a system of professional and personal competencies of a teacher, ensuring the effective implementation of meaningful and targeted types of pedagogical activity;

- meanings: to serve the demanded subject-oriented type of the pedagogical process, while the updated didactic knowledge is used by the future teacher to construct the subjective level of his professional experience, self-awareness, his senses and needs for self-education and self-realization, primarily through overcoming the impersonal approach and the formation of an integral person ;

- content: a) in the logic of the anthropocentric concept: (Bolotov V.A., Levitsky M.L., Remorenko M.I., Serikov V.V.): a system of meanings, indicative foundations and experience of the future teacher's implementation of goal-setting, motivating, teaching, developmental and educational functions of a teacher (p. 39 monograph); an integrative construct of the content of education, as the teacher's readiness for the human-developing 
mission of the educational process - the development of the student's ability to be an active subject of his own life and socio-cultural progress;

b) in the logic of the technocratic paradigm: filling the professional baggage of future teachers with a set of didactic solutions, forming the ability to design such solutions based on modern pedagogical knowledge.

- technologies used in the training of teachers: an extensive range of educational and didactic tools, including digital ones, in order to ensure the development of teacher competencies and their integration into holistic professional competence

The convergence of the traditional and information educational environment is implemented in the teacher training system in the following aspects:

- integration of forms, methods and technologies used in teaching future teachers at the university, based on the emergence of new types of educational reality: virtual, mixed, online;

- integration of personal, social and professional self-determination of teachers as a guarantee of continuous education throughout life and professional success;

- integration of educational and project activities during training at a university and in institutions of additional professional education;

- integration of subject disciplinary structure and interdisciplinary, transdisciplinary structure of training courses.

As a conceptual basis for teacher training, it is necessary to highlight interdisciplinary and personalized approaches. An interdisciplinary approach will allow for the conceptual integration of requirements for a future teacher based on the orientation of pedagogical education to the formation of a cultural and professional profile of a teacher in an open educational environment in accordance with international scientific trends and innovative educational practices. On the basis of a personified approach, it is possible to substantiate the requirements for the formation of the personal meaning and value of the future profession and to consider professional activities in the context of an integral, dynamic, multi-level, complex system in which the teacher must maintain a dynamic balance between traditional and innovative education and develop the ability to generate new forms and ways of teaching and upbringing, including taking into account the formation of a digital educational environment.

The organization of a regional digital educational environment for the training of pedagogical personnel should be based on the regulatory documents of the Russian Federation in a single educational space. The digital educational environment includes a set of information systems and all participants in the educational process: students of pedagogical universities, teachers of educational institutions of different levels and different qualifications (young teachers, professionals and teacher-mentors), managers in the field of pedagogical education, representatives of public and expert councils of the region ...

The digital educational environment of the region in the preparation of teachers is characterized by the following aspects:

- a complex of information educational resources;

- a set of technological tools (the use of modern pedagogical and information technologies); - organization of network interaction of participants in the educational process.

At the second stage of the study, a critical analysis of the pedagogical educational models of the Southern Federal University (Southern Federal District), Kaluga State University named after V.I. K.E. Tsiolkovsky (as part of the regional teacher training system) implemented in the digital educational environment. The strategies for the development of universities, curricula, basic educational programs for the training of future teachers, the organization of a digital educational environment were analyzed. The following criteria were chosen for the analysis: 1) the content of pedagogical education - a 
system of meanings, indicative foundations for the implementation by a future teacher of goal-setting, motivating, teaching, developmental and educational functions of a teacher and the presence of interdisciplinary courses in the curriculum; 2) the conditions for the inclusion of the student himself in the process of designing the content and technologies of his education through the implemented learning technologies and practice; 3) mechanisms for the development of motivational and semantic components of professional activity in the educational environment of the university; 4) availability of courses that take into account the bilingual and multiculturalism of the region; 5) the quality of the organization of the digital educational environment in the region.

The analysis showed that all the criteria are most fully implemented at the Southern Federal University, which compiled the design of teacher education, designed in such a way as to provide all students with flexible individual trajectories to pedagogical professional activity. The system of pedagogical education at the university consists of components that reveal the value foundations, personal meanings and project components of professional activity. The training modules, into which the teacher training program is divided, allow the integration of interdisciplinary courses and psychological preparation of students for the profession through open sets of professional competencies and psychological intensive. The implementation of the module, which begins with input competence control and psychometric diagnostics, creates favorable conditions for the active participation of students in the process of their own learning. Since all modules involve the assembly of the educational space, practical and independent work and the protection of projects, this allows, during the entire period of training, to create a model of future professional activity and its essential characteristics. Motivational and semantic components are formed in future teachers both on educational models through reflection of individual educational tasks, and in the course of tutor support of students during the entire period of study [4]. A digital educational environment has been created in the Southern Federal District, in which horizontal and vertical interaction is organized between the participants of the educational cluster of the region: specialized pedagogical classes, students of pedagogical universities, teachers of various qualifications. Networking was organized based on the joint development and use of training courses. However, in the process of organizing a regional digital environment for teacher training, its possibilities for building an individual trajectory of teacher professional growth are not taken into account, training is not provided taking into account the possibility of building a bilingual and multicultural environment; the role of teacher education managers is not defined in this network interaction; the conceptual foundations for organizing the systemic interaction of the participants have not been formed; the possibilities of online self-identification of teachers have not been fully understood, although there is a partial convergence of traditional and information educational environments: in the field of integration of activities: educational and project; use in teaching different forms of interaction: online, mixed, virtual.

The Kaluga Region is one of 14 pilot projects of the Russian Federation, in which it is planned to implement a digital educational environment in educational institutions of general and secondary vocational education for conducting lessons in a mixed format and carrying out certification of students. Therefore, we analyzed the organization of the digital educational environment at the Kaluga State University named after K.E. Tsiolkovsky, in which the project "Pedagogical Institute" is being implemented, within the framework of which the model of the organization of the educational process of teachers has been substantially changed: from linear to nonlinear and pedagogical logistics, from standardized to individual-team. Trainees are included in the learning process by building individual educational trajectories and group command routes. The university has developed systemic vocational guidance and reflective analysis of the formation of 
professional identity. A digital educational environment has been partially formed, in which students of a pedagogical university can partially interact within the framework of practical classes, post digital portfolios, however, the mechanisms and technologies for forming the value foundations of future professional activities and the implementation of interdisciplinary training courses are not fully covered.

According to the conducted quantitative and qualitative analysis of the digital educational environment for training teachers in both regions under consideration, it was revealed that the constituent entities of the Russian Federation have certain resources for this: the regulatory framework for this; electronic educational universities in universities; partial networked educational environment. However, there are no projects for the development of a digital educational environment for organizing network interaction of all participants in the pedagogical system of the region, their roles and powers are not defined, the risks of interaction in an environment using the Internet and other information systems are not identified, and a digital platform for organizing such an environment has not been chosen. At the same time, the following positive trends were revealed in the field of organizing pedagogical education in the region:

1) the desire to individualize the professional training of future teachers: innovative independent work of students (quests of different thematic focus, the inclusion of students in professional pedagogical communities, the organization of pedagogical workshops for reflective practices and trainings with the aim of psychological preparation of teachers for future activities); implementation of projects aimed at cooperation in the field of research activities of university students and educational and methodological activities of school teachers in the region; variability of curricula for the possibility of building individual educational routes;

2) the content of pedagogical education is a continuous system of training at different levels: bachelor's, master's, postgraduate studies, professional development of teachers and has the following characteristics: universality, versatility, integration of theory, practice and the technological aspect, fundamentality and humanization;

3 ) the priority of the organization of project activities - as an indicator of the formation of professional competencies of students.

\section{Conclusions}

The digital educational environment of the region is characterized by a set of information systems included in it, the involvement of new subjects in the educational process and an increase in the proportion of self-organization of educational activities, as well as the integration unity of different learning formats; horizontal convergence within the network interaction of teachers in the region; the convergence of personal, social and professional self-determination of teachers based on the combination of real educational reality and virtual reality; uncertainty and unpredictability due to the rapid pace of development of all spheres of social life. It is characterized by the characteristics of transnationality, polysubjectivity and variability, which requires the modernization and transformation of the regional system of pedagogical education. Improving the quality of teacher education in the constituent entities of the Russian Federation is inextricably linked with several aspects: organization of a regional continuous system of pedagogical education based on the determination of the personal growth of students in the process of studying at a university and teachers in the process of their professional activities, taking into account the technological capabilities of the digital educational environment. It is necessary to modernize the content side of pedagogical education with a shift in emphasis from the process of forming competencies as the basis for training to a personal and professional system of values, motives and goals that is significant for future teachers. It has been 
established that the universities are working towards individualization and personification of the training of future teachers, however, in the institutions of additional professional education of teachers, such a trend has not been noticed. We have defined the functions of pedagogical education, the systematic and comprehensive implementation of which will improve the quality of pedagogical education in new educational conditions: 1) diagnostic and self-diagnostic: identifying the student's personal potential and his self-diagnosis in order to correlate his own psychophysiological and functional characteristics with the requirements of the pedagogical profession and determine deficiencies ; 2) project: building personal educational routes [1] and "points of growth", including taking into account different forms of education at the university and preparation for the specifics of education in the digital environment; 3) constructive: the design of educational programs with the possibility of an expanded variable choice of academic disciplines and practices; design of the content of work programs of disciplines, taking into account the results of diagnostics and self-diagnostics; 4) technological: the choice of teaching technologies, taking into account the specifics of the university environment (socio-cultural, multicultural, blended learning, etc.); 5) creative-forming: the development of the creative potential of students, taking into account the specifics of pedagogical activity and the formation of the ability to quickly respond to changing conditions of the external environment in education; 6) acmeological: the development of the individual multifaceted potential of students in the field of pedagogical activity; 7) axiological: the formation of a system of personal and professionally significant values; 8 ) adaptive: creating conditions for the adaptation of a student in a developing and changing pedagogical educational environment in order to form compensatory mechanisms for future professional activity, including taking into account the specifics of online education; 9) reflexive: the definition of criteria and forms of assessment of the formed competencies of future pedagogical activity on the basis of personal meanings and built personal educational routes.

\section{References}

1. M. Kapshutar, Personal meanings of liberal arts education, Basic Research, 11, 59-60 (2006)

2. O. Popova, Personalized information technologies in the processes of socialization of the individual, Personalized information technologies in the processes of socialization of the individual and the economy, 6-10 (2006)

3. V. Gunchina, The Phenomenon of Professional Self-Identification, Young Scientist, 15.2, 59-64 (2017)

4. A. Bermus, M. Bondarev, V. Kirik, I. Kulikovskaya, R. Chumicheva, Concept for the development of pedagogical education in a federal multidisciplinary university (on the example of SFedU), Pedagogical education in modern Russia: strategic development guidelines: monograph, 619-652 (2020)

5. O. Gukalenko, S. Ivanova, N. Selivanova, V. Pustovoitov, Social and educational space of pedagogical education: the experience of the formation and design of the future, Pedagogical education in modern Russia: strategic guidelines for development: monograph, 231-257 (2020)

6. N. Safontseva, Development of Student Professional Competence at Pedagogical Universities as a Result of Mastering the Educational Program, Humanities and Social Sciences, 6, 287-295 (2019) 
7. M. Levitsky, V. Grinshkun, Immersive Technologies: Ways of Complementing Virtuality and the Possibility of Their Use in Education, Bulletin of the Moscow State Pedagogical University, 3 (53), 21-25 (2020)

8. V. Popova, Formation of Design Skills of University Students, Traditions and Technogenic Civilization: Problems of Interaction, 261-268 (2010)

9. T. Kulikova, N. Poddubnaya, Improving the Professional Competence of a Teacher in Arranging Project Activities of Students, Informatics and Education, 1 (280), 38-41 (2017)

10. Yu. Yurova, L. Filimonyuk, Design and Methodological Activity of an Extracurricular Teacher, World of Science, Culture and Education, 4, 88-92 (2019) 